\title{
BMJ Open Economic burden of road traffic injuries in sub-Saharan Africa: a systematic review of existing literature
}

\author{
Marcella Farrelle Dorothea Ryan-Coker (D) , ${ }^{1,2}$ Justine Davies, ${ }^{3}$ Giulia Rinaldi, ${ }^{4}$ \\ Marie Hasselberg, ${ }^{5}$ Dennis H Marke, ${ }^{1}$ Marco Necchi, ${ }^{1}$ \\ Hassan Haghparast-Bidgoli (iD ${ }^{2}$
}

To cite: Ryan-Coker MFD, Davies J, Rinaldi G, et al. Economic burden of road traffic injuries in sub-Saharan Africa: a systematic review of existing literature. BMJ Open 2021;11:e048231. doi:10.1136/ bmjopen-2020-048231

- Prepublication history and additional supplemental material for this paper are available online. To view these files, please visit the journal online (http://dx.doi.org/10.1136/ bmjopen-2020-048231).

Received 21 December 2020 Accepted 28 August 2021

Check for updates

(c) Author(s) (or their employer(s)) 2021. Re-use permitted under CC BY-NC. No commercial re-use. See rights and permissions. Published by BMJ.

${ }^{1}$ Emergency Hospital, Goderich Surgical Centre, Freetown, Sierra Leone

${ }^{2}$ Institute for Global Health, University College London, Faculty of Population Health Sciences, London, UK

${ }^{3}$ Institute of Applied Health Research, University of Birmingham, Birmingham, UK ${ }^{4}$ Guy's and Saint Thomas' Hospitals NHS Trust, London, UK ${ }^{5}$ Department of Global Public Health, Karolinska Institute, Stockholm, Sweden

Correspondence to Hassan Haghparast-Bidgoli; h.haghparast-bidgoli@ucl.ac.uk

\section{ABSTRACT}

Objective This systematic review aims to explore and synthesise existing literature on the direct and indirect costs from road traffic injuries (RTIs) in sub-Saharan Africa (SSA), the quality of existing evidence, methods used to estimate and report these costs, and the factors that drive the costs.

Methodology MEDLINE, SCOPUS, ProQuest Central, Web of Science, Global Index Medicus, Embase, World Bank Group e-Library, Econlit, Google Scholar and WHO webpages were searched for relevant literature. References of selected papers were also examined for related articles. Screening was done following the Preferred Reporting Items for Systematic Reviews and Meta-Analyses (PRISMA) guidelines. Articles were included in this review if they were published by March 2019, written in English, conducted in SSA and reported original findings on the cost of illness or economic burden of RTIs. The results were systematically examined, and the quality assessed by two reviewers using a modified Consolidated Health Economic Evaluation Reporting Standards (CHEERS) checklist.

Results Eleven studies met the inclusion criteria. RTIs can cost between INT\$119 and 178634 per injury and INT\$486 and 12845 per hospitalisation. Findings show variability in costing methods and inadequacies in the quality of existing evidence. Prolonged hospital stays, surgical sundries and severity of injury were the most common factors associated with cost.

Conclusion While available data are limited, evidence shows that the economic burden of RTIs in SSA is high. Poor quality of existing evidence and heterogeneity in costing methods limit the generalisability of costs reported.

\section{INTRODUCTION}

According to the 2016 global burden of disease estimates, road traffic injuries (RTIs) are the eighth leading cause of death across all ages and the number one cause of death among children and young adults aged 5-29 years, ranking above infectious diseases such as malaria and tuberculosis. ${ }^{12}$ Without action, it is projected that by 2030 , RTIs will be the fifth leading cause of death worldwide. $^{3}$
Strengths and limitations of this study

- The information presented in this study fills the gap in the existing literature surrounding the economic burden of road traffic injuries in sub-Saharan Africa.

- This study used a universally acceptable and best practise tool (the Consolidated Health Economic Evaluation Reporting Standards checklist) to assess the quality of reporting done by the reviewed studies.

- Due to the heterogeneity of the cost components, lack of transparency in resource estimation, variability in unit costs and costing methods, it is difficult to comparatively analyse the results of the review.

Despite being targeted in the global sustainable development goals, as at 2016, the RTI mortality rate globally has remained constant at about 18 per 100000 population with a steady increase in absolute numbers; more than 1.3 million deaths, and around 20-50 million injuries each year. ${ }^{14}$ More than $90 \%$ of this RTI burden is borne by low-income and middle-income countries (LMICs) in subSaharan Africa (SSA) and South-East Asia. ${ }^{5}$ The RTI mortality rate in Africa (26.6 per 100000 ) is the highest globally and thrice as high compared with Europe. ${ }^{1}$ While data on the burden of RTIs and disabilities in SSA are limited (most data on burden are modelled rather than based on direct observation), estimates suggest that Africa accounts for $3 \%$ of total healthy life lost and makes up 21.6\% of the disability adjusted life years lost due to RTIs. ${ }^{2}$ Hence, RTIs have been described as the "third burden of disease in SSA. ${ }^{6}$ The death toll of RTIs in SSA has increased by more than $80 \%$ over the last three decades and is projected to increase by $80 \%$ or more in 2020 if action is not taken. ${ }^{7}$

However, the financial burden that individuals, their families, employers and societies bear as a consequence of RTIs in SSA is 
under-reported. ${ }^{89}$ In many countries in SSA, insurance and social protection schemes are not widely available, so expenses are borne by victims and their families. ${ }^{1011}$ Thus, RTI victims and their families can become impoverished or experience debts or catastrophic health expenditure due to direct medical costs of accessing care and income loss because of the injury and care access. ${ }^{12}$ These losses negatively impact the economy and national development. Globally, countries lose between $1 \%$ and 3\% (estimated at more than US $\$ 500 \mathrm{bn}$ ) of their gross domestic product (GDP) to RTIs every year. ${ }^{14}$ The economic consequences are estimated to be worse for SSA, where many countries have developing economies and underdeveloped health systems. GDP loss as a result of RTIs in Africa is between $0.8 \%$ and $9 \% .{ }^{15}$ For some countries, this loss is more than the total aid they receive per year. ${ }^{516}$

Data on the epidemiology of RTIs in SSA are lacking compared with high-income countries, but accurate information on costs attributed to RTIs in SSA is even more scarce. ${ }^{17}$ To prioritise and implement cost-effective interventions for road safety that prevent RTIs, the economic burden of RTIs and its impact on the national economy should be understood. ${ }^{1}$ This study aims to understand the economic burden of RTIs in SSA. It examines existing literature on the costs associated with RTIs in SSA with the specific objectives of: (1) reviewing the direct and indirect costs of RTIs, (2) assessing the quality of existing evidence and the methods used to estimate and report costs of RTIs and (3) identifying the drivers of the cost reported.

\section{METHODS}

\section{Search strategy}

Search terms used are shown in detail in online supplemental file 1. All countries in SSA (SSA was defined as 48 countries per the World Bank ${ }^{18}$ ) were included individually in the search strategy to maximise the results.

Combinations and adaptations of the search terms were used in independent searches in the following databases: MEDLINE, SCOPUS, ProQuest Central, Web of Science, Global Index Medicus, Embase, World Bank Group e-Library and Econlit. A hand search was employed to source grey literature and unindexed data in Google scholar and $\mathrm{WHO}$ webpages. All results were returned for these searches.

\section{Inclusion and exclusion criteria}

Studies were included in this review based on the following criteria: written in English, related to SSA and report original findings on the cost of illness or economic burden of RTIs using primary or secondary data, regardless of the anatomic location or mechanism of the injury. The literature search was conducted in March and April 2019, and this review included all studies published before 1 March 2019.

Articles were excluded if they were poster and conference abstracts, without cost or cost analysis, reported general trauma instead of RTIs, reported costs of road safety interventions and without available full texts. This systematic review followed the Preferred Reporting Items for Systematic Reviews and Meta-Analyses (PRISMA) guidelines. ${ }^{1920}$ The selection and screening process of the articles using the PRISMA guidelines is shown in figure 1.

\section{Data extraction and quality assessment}

Following screening and retrieval of articles for review, relevant data were obtained using a tailored extraction tool, created from existing guidelines for economic evaluation and similar tools from peer-reviewed articles. ${ }^{21-23}$ The screening was done initially based on the titles, then the abstracts and references of the chosen text, and finally, the full texts were screened for eligibility. General characteristics such as country and year of study, study design, whether primary or secondary data were utilised and economic features such as type of cost (direct or indirect) reported, time horizon, the perspective of the analysis, costing methods and the factors that drive these costs were extracted from the articles and tabulated. Perspectives were described as societal (if they included all direct and indirect costs taking into consideration every member of a society), patient (if they included outof-pocket medical and non-medical expenditures and loss of wages), provider (if they estimated cost of delivery of care at the care facility and services were provided to the patients free of charge) or mixed if they took more than one perspective. Drivers of costs are presented as reported in the studies. For studies that did not explicitly state the drivers of the cost, elements that identified or reported to increase expenditure were presumed to be drivers.

Several checklists have been widely used to assess the quality of methods and reporting of economic evaluations. The Consolidated Health Economic Evaluation Reporting Standards (CHEERS) checklist is widely used and sometimes modified for use in cost of illness studies. ${ }^{24}$ This study used a modified version of the CHEERS checklist, similar to a version used by Rinaldi, Hijazi and Haghparast-Bidgoli in their partial economic evaluation. ${ }^{25}$ The modified checklist (online supplemental file 2) consists of 16 elements, designed to assess the quality of reporting of partial economic evaluation and cost of illness studies. Items on the checklist were scored 'yes' if they met the criteria, 'partly' if they only met the criteria partially or 'no' if they did not meet the criteria. Two reviewers (MFDR-C and GR) independently extracted data from the included studies and reviewed the quality of the studies; any disagreement was resolved by a third reviewer (HH-B).

\section{Analytic framework}

Costs were adjusted to account for inflation (in local currencies) using Consumer Price Index data for each country, ${ }^{26}$ and then converted to 2018 International Dollars (INT\$).

Where stated, the costing year was used as a baseline to account for inflation; if costing year was not reported, the 


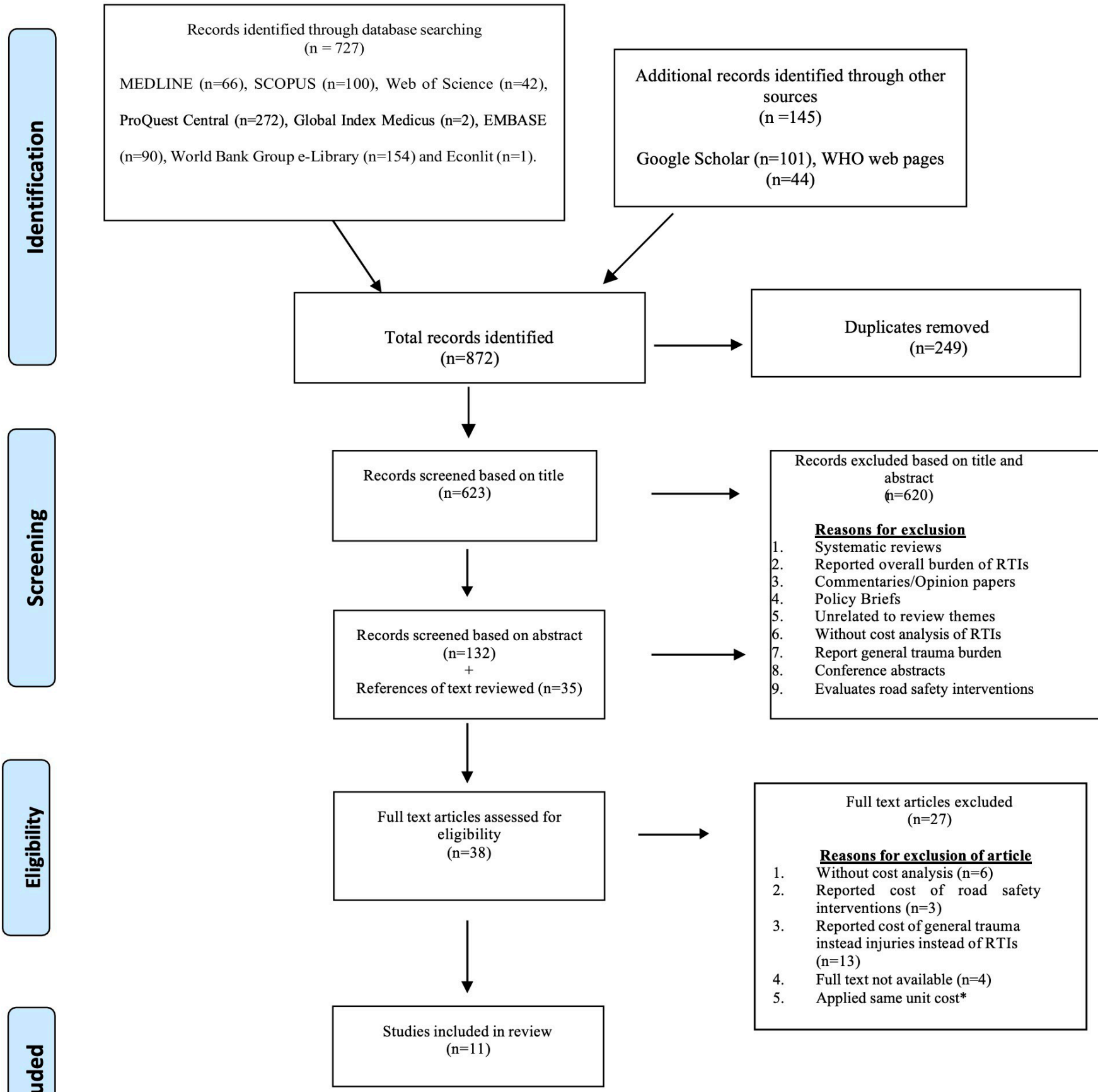




\section{Cost estimates/evaluations}

The economic burden of RTIs was determined using the costs from the individual studies. These costs were categorised as direct medical costs, direct non-medical costs, and indirect costs.

Direct costs include all costs incurred from the use of healthcare services. ${ }^{29}$ For this review, we used Drummond et al definition of direct medical and non-medical costs. ${ }^{30}$ Costs resulting from visits to the accident and emergency department, inpatient stays, outpatient visits, radiological and laboratory investigations, surgical procedures and implants, medicines, wound care and specialist care and consultation were considered as direct medical costs. Direct non-medical costs were those resulting from the cost of transportation to receive care, administrative costs (such as cost related to police investigations), cost of insurance, costs incurred by family members while they support the injured patient, medicolegal costs and funeral costs.

Indirect costs covered productivity losses, intangibles (pain, grief and suffering) and mortality resulting from the injury. ${ }^{29} 30$ The type of cost analysed, and the average unit costs presented in each study were extracted and tabulated.

The average unit costs are shown as reported in the original studies, per injury and hospitalisation. For studies that reported only total cost without unit costs, the average cost per patient was estimated by dividing the total cost by the sample size. For this study, cost per injury and cost per (injured) patient are the same.

\section{Patient and public involvement}

Since this study is a systematic review of academic literature, there is no direct patient and public engagement in process of conducting this study.

\section{RESULTS}

The initial search from all sources (databases and grey literature) yielded 872 results. After removing duplicates, 623 articles were screened through the various stages (figure 1). In the title and abstract screening stages, articles that were systematic reviews, conference abstracts, policy papers, those that reported overall trauma burden (not specifically RTIs) or without cost analysis, and those that did not directly relate to the themes of this were excluded. Articles that could not be excluded based on the abstract and titles were included for full-text reviews. The full texts of 38 articles were reviewed, and 12 studies met the inclusion criteria. Twenty-six articles that did not have cost analysis or reported the cost of road safety interventions or the costs of general trauma, and those whose full texts were unavailable were excluded. One of the studies that met the inclusion criteria was excluded because the exact unit costs were applied for two studies in the same country, one applied at provincial and the other at a national level. ${ }^{31}$

\section{General characteristics of the studies}

A summary characteristic of the reviewed studies is shown in table 1 . The results highlighted an apparent disproportion in the spread of RTI-cost research across SSA regions. Of the 11 studies, five were done in West, three in Southern, two in Central and one in East Africa. Only six of the 48 SSA countries were represented in these studies: Nigeria (4), South Africa (3), Rwanda (1), Cameroon (1), Ghana (1) and Kenya (1).

All studies were conducted between 1998 and 2016, with $64 \%(n=7)$ being done in the last decade. Forty-five percent $(n=5)^{1032-35}$ of studies looked specifically at RTIs involving motorcycles, whereas the other $55 \%$ looked at RTIs in general (data not shown). Although the majority $(91 \%)$ included all injuries resulting from RTIs, one ${ }^{33}$ focused exclusively on dentofacial injuries among motorcycle crashes. Nine (82\%) studies were carried out in urban settings, one in a rural setting, and one involved both urban and rural settings.

Study design was explicitly stated in $64 \%(n=7)$. Seventy-one percent of the reported designs were retrospective, and $29 \%(n=2)$ were prospective. For the remaining $36 \%$ $(n=4)$, the reviewers determined the study design based on the information provided in the studies. On this basis, two studies were considered retrospective designs, and two employed both prospective and retrospective designs.

Nine studies $(82 \%)$ specified a time horizon. ${ }^{1032-39}$ All the time horizons reported were 13 months or less, and as such, costs did not require to be discounted.

None of the studies explicitly stated the perspectives taken. All perspectives summarised in table 1 are based on the reviewers' evaluation of the papers. The most described perspectives in the articles were patient $(55 \%)$ and societal $(36 \%)$. Only one article $(9 \%)$ was deemed to have taken a provider perspective.

Exclusive primary data collection was used in $45 \%(n=5)$ of studies, $18 \%(n=2)$ utilised secondary data collection methods and $36 \%(n=4)$ made use of both data sources.

\section{The costs of RTls}

The costing methodology and results of the reviewed studies are summarised in table 2. All 11 studies reported direct medical costs. Overall, seven studies (64\%) reported more than one type of cost, but only one ${ }^{36}$ reported direct and indirect costs as separate results.

More than half of the reviewed articles (63\%) did not state their costing method. Of those that did, three ${ }^{33} 35$ used a gross output approach, one ${ }^{36}$ utilised mixed methodology (top-down and bottom-up approaches), and one $^{39}$ was a micro-costing study.

Concerning the units of cost reported, $45 \%(n=5)$ of studies reported costs per injury, and $55 \%(n=6)$ reported cost per hospitalisation. Ten (91\%) studies presented their findings as average unit cost per patient, while one study $^{32}$ presented their findings as total costs. One study presented separate costs per severity of injury (slight/ minor, serious/major and fatal injuries). ${ }^{40}$ Matinawe and Mahomed $^{36}$ reported cost per patient per day; for this, 
Table 1 Summary characteristics of the reviewed studies

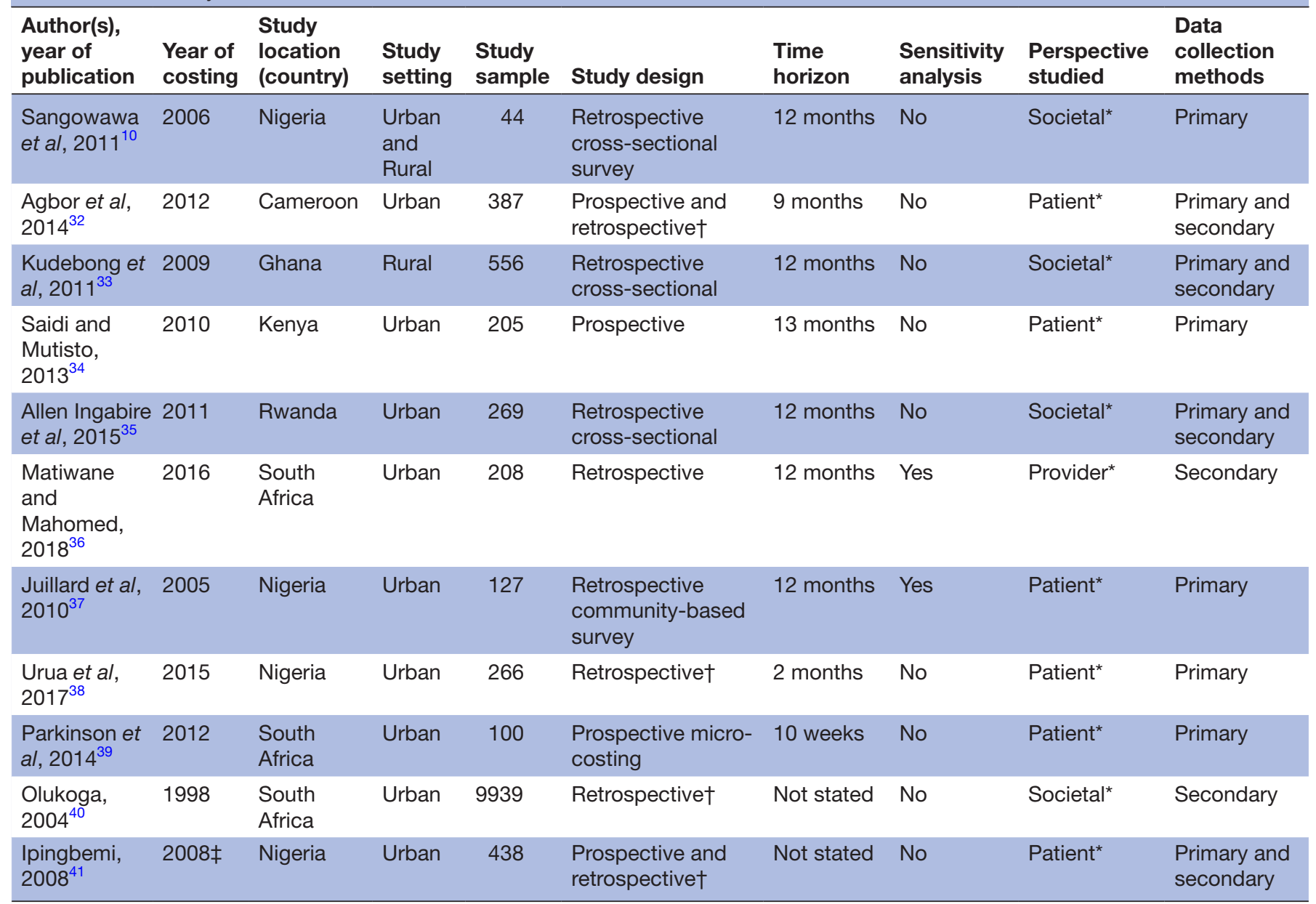

*Perspective not specified, so the reviewers' evaluation was applied.

†Study design not mentioned in paper, so the reviewers' perspective was applied.

¥Year of costing not stated, so the year of publication was used.

the average cost per hospitalisation per patient was estimated by multiplying the average cost per patient per day by the average length of hospital stay of patients. Per hospitalisation costs ranged from INT $\$ 486$ to 12845 with an IQR of 8887.5 and median cost of INT $\$ 1291.5$, while costs per injury ranged from INT $\$ 119$ to 178634 with an IQR of 40391 and median cost of INT\$10 906.

Regarding the components of costs presented, $73 \%$ $(n=8)$ of studies described a breakdown of the cost components. ${ }^{10} 32$ 35-40 The components of costs are presented in table 3. The most measured components of direct medical costs were surgical procedures and medications. The most measured direct non-medical costs were property damage, funeral cost, and administrative costs.

Considering the factors that drive the costs of RTIs, only $18 \%(n=2)$ clearly stated the drivers of costs observed in their studies. ${ }^{36}{ }^{39}$ For six other studies, this was inferred based on the information presented on cost components in the papers. ${ }^{32-35} 3738$ For the remaining three studies, no information was presented on the cost components and so it was not possible to determine the drivers of the cost. $^{104041}$ The reported costs are higher in studies that involved urban compared with rural areas. However, a direct comparison cannot be made as a result of heterogeneity in methodologies. Prolonged hospital stays, surgical sundries and severity of injury were observed to have the most influence on cost increment.

\section{QUALITY OF REPORTING EVIDENCE AND COSTING METHODOLOGY}

The results of the quality assessment of the studies are summarised in figure 2 and reported in online supplemental file 2. Overall, only four $(36 \%)$ of the reviewed articles met $50 \%$ or more of the checklist criteria. ${ }^{32} 353639$ Two of them met around $60 \%$ or more of the criteria, ${ }^{36} 37$ and only one met more than $80 \%$ of the criteria. ${ }^{36}$ No study met all the criteria in the checklist.

Items 1 and 3 (title and background/objectives, respectively) were most often met. Eight studies (73\%) identified their report as a costing study in the title, and all 11 studies gave enough background information and indicated the aims and objectives of their studies. 
Table 2 Costing methodology and economic features of the reviewed studies

\begin{tabular}{|c|c|c|c|c|c|c|c|}
\hline Author, year & $\begin{array}{l}\text { Study } \\
\text { location }\end{array}$ & Cost (INT\$) & $\begin{array}{l}\text { Unit } \\
\text { (mean per) }\end{array}$ & $\begin{array}{l}\text { Costing } \\
\text { methodology }\end{array}$ & $\begin{array}{l}\text { Components } \\
\text { of cost } \\
\text { described }\end{array}$ & $\begin{array}{l}\text { Drivers } \\
\text { of cost } \\
\text { identified }\end{array}$ & $\begin{array}{l}\text { Types of cost } \\
\text { presented }\end{array}$ \\
\hline $\begin{array}{l}\text { Sangowawa et al, } \\
2011^{10}\end{array}$ & Nigeria & 187 & Per injury & Not specified & Yes & No & $\begin{array}{l}\text { Direct and } \\
\text { indirect costs }\end{array}$ \\
\hline $\begin{array}{l}\text { Agbor et al, } \\
2014^{32}\end{array}$ & Cameroon & 486 & $\begin{array}{l}\text { Per } \\
\text { hospitalisation }\end{array}$ & Not specified & No & Yes* & Direct cost \\
\hline $\begin{array}{l}\text { Saidi and Mutisto, } \\
2013^{34}\end{array}$ & Kenya & 1129 & $\begin{array}{l}\text { Per } \\
\text { hospitalisation }\end{array}$ & Not specified & No & Yes $^{*}$ & Direct cost \\
\hline $\begin{array}{l}\text { Allen Ingabire et } \\
\text { al, } 2015^{35}\end{array}$ & Rwanda & 14193 & Per injury & Gross output & Yes & Yes $^{*}$ & $\begin{array}{l}\text { Direct and } \\
\text { indirect costs }\end{array}$ \\
\hline $\begin{array}{l}\text { Juillard et al, } \\
2010^{37}\end{array}$ & Nigeria & 119 & Per injury & Not specified & Yes & Yes $^{*}$ & $\begin{array}{l}\text { Direct and } \\
\text { indirect costs }\end{array}$ \\
\hline Urua et al, $2017^{38}$ & Nigeria & 588 & $\begin{array}{l}\text { Per } \\
\text { hospitalisation }\end{array}$ & Not specified & Yes & Yes $^{*}$ & Direct cost \\
\hline $\begin{array}{l}\text { Parkinson et al, } \\
2014^{39}\end{array}$ & South Africa & 12845 & $\begin{array}{l}\text { Per } \\
\text { hospitalisation }\end{array}$ & Micro-costing & Yes & Yes & Direct cost \\
\hline Olukoga, $2004^{40}$ & South Africa & $\begin{array}{r}10906 \\
40578 \\
178634\end{array}$ & $\begin{array}{l}\text { Per minor injury } \\
\text { Per major injury } \\
\text { Per fatal injury }\end{array}$ & Not Specified & Yes & No & $\begin{array}{l}\text { Direct and } \\
\text { indirect costs }\end{array}$ \\
\hline
\end{tabular}

${ }^{*}$ Reviewers identified cost drivers.

†Cost per injury derived from the total cost.

The least often met criteria were items 6,11 and 13 in the methodology section (study perspective, analytical methods and characterising uncertainty in that order). All 11 studies failed to specify what perspectives they took. Only one study detailed their analysis and considered the effect of sampling uncertainty. ${ }^{36}$ Juillard $e t$ al reported performing analysis but did not provide any detail. ${ }^{37}$ Only two studies described analytic methods fully. ${ }^{36}{ }^{37}$ One study, ${ }^{10}$ partially fulfilled the analytic methods criteria, and eight $(73 \%)$ did not describe any method of analysis. Studies were not discounted as is expected since all the time horizons stated were 13 months or less.

Other benchmarks that were not achieved in the methodology section were estimating resources and cost (item 9) and providing information on currency, price date and conversion methods used (item 10). Only 18\% ( $\mathrm{n}=2$ ) of studies presented information on the approaches used to identify, measure and value resources. Fortyfive $(45 \%)$ presented incomplete information and $36 \%$ did not report the approaches used. For three of the studies reviewed, ${ }^{34} 37$ the main objectives were not to estimate the costs of the injuries, so they mostly lacked the information necessary to fulfil this criterion. Identical findings were observed for reporting evidence on the currency and conversion methods (see figure 2).

In the results section, an inadequately met criterion was the presentation of costs (item no. 12). One-third of the reviewed studies provided comprehensive breakdowns of the different cost components measured and two-thirds stated what type of cost was being estimated. One study ${ }^{34}$ did not provide any detail in this regard.

Concerning the discussion section, $55 \%(n=6)$ of studies presented results that were in line with their objectives, summarised their essential findings, explained how they arrived at their reported conclusions, acknowledged the limitations in their work and discussed its generalisability and where it sits within the broader literature on the topic (item 14). Of the $45 \%(n=5)$ that only partially met this criterion, two did not discuss limitations or how transferrable their study results were. Of note was a similarity in the limitations highlighted in three of the studies. ${ }^{32} 3739$ They all noted a possible underestimation of the actual cost as a result of sources of data, assumptions made, potential biases and costing methodologies. 
Table 3 Components of costs reported

\begin{tabular}{|c|c|}
\hline Cost variables & $\mathbf{N}$ \\
\hline \multicolumn{2}{|l|}{ Direct medical cost } \\
\hline Hospital stay/bed space & 3 \\
\hline Investigations (radiology) & 3 \\
\hline Investigations (laboratory) & 3 \\
\hline Surgical procedures & 4 \\
\hline $\begin{array}{l}\text { Simple procedures such as catheterisation, } \\
\text { nasogastric tube, wound dressing }\end{array}$ & 2 \\
\hline Prosthetics/orthopaedic implants & 3 \\
\hline Enteral feeding & 2 \\
\hline Medications & 4 \\
\hline Blood transfusion & 2 \\
\hline Intensive Care Unit (ICU) care & 1 \\
\hline Consultation fees & 1 \\
\hline Physiotherapy & 1 \\
\hline $\begin{array}{l}\text { Medical consumables (such as cotton wool, gloves } \\
\text { and diapers) }\end{array}$ & 2 \\
\hline Medical cost & 5 \\
\hline \multicolumn{2}{|l|}{ Direct non-medical cost } \\
\hline Transportation & 1 \\
\hline Feeding & 1 \\
\hline $\begin{array}{l}\text { Miscellaneous out of pocket (OOP) spending (such } \\
\text { as toiletries, drinking water and disinfectants) }\end{array}$ & 3 \\
\hline Property damage resulting from the crash & 3 \\
\hline Funeral costs & 3 \\
\hline Administrative costs (such as insurance and police) & 3 \\
\hline Legal costs & 2 \\
\hline \multicolumn{2}{|l|}{ Indirect cost } \\
\hline Loss of output & 5 \\
\hline Disability & 2 \\
\hline Days of work/job lost & 2 \\
\hline Pain and suffering & 3 \\
\hline $\begin{array}{l}\text { Miscellaneous costs (such as visiting times to } \\
\text { hospitals, repair shops, attending funerals, flowers } \\
\text { and telephone cards) }\end{array}$ & 2 \\
\hline Employee compensation & 1 \\
\hline
\end{tabular}

Stating sources of funding (item no. 15) was also an area of glaring weakness. Only $36 \%(n=4)$ of the articles detailed their sources of funding.

\section{DISCUSSION}

To the authors' best knowledge, there is no existing systematic review on the economic burden of RTIs in SSA. The findings of this study demonstrate a dearth of existing data and research on the topic in and across the SSA region. It also shows that regardless of the limitations in the available data, the economic burden of RTIs is substantial and varies by country. Furthermore, it

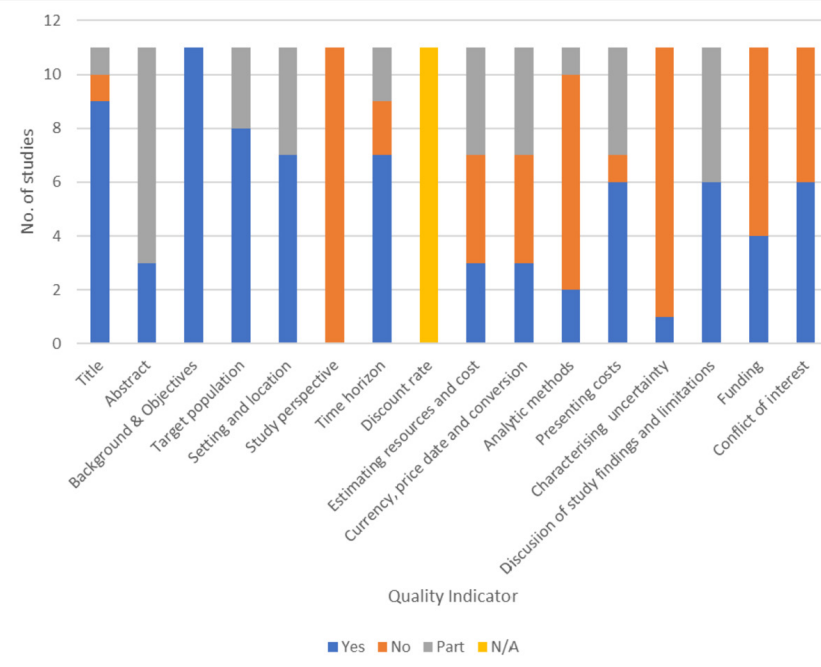

Figure 2 Quality of reporting in the selected studies.

highlights the unsatisfactory quality of reporting of the existing evidence and the need for improvement. Finally, it suggests that the length of hospital stay, and surgical sundries are the most common associated factors with the cost of RTIs.

The first objective set out in this study was to review the published literature on the economic burden and costs of RTIs in SSA. The findings indicate that although more studies have been done in the last decade, huge gaps exist in available evidence across SSA. Only six countries in SSA were represented in the studies. This lack of geographic representation is consistent with information published by WHO highlighting the gaps in RTI research across SSA. ${ }^{42}$ The results of this study also show that a substantial number of the studies are conducted in urban than rural settings, similar to findings from Wesson et al review on RTIs in LMIC. ${ }^{43}$ However, although not explicitly specified in the studies reviewed, it should be acknowledged that the majority of urban studies are conducted in hospitals that cover both urban and rural populations. Nevertheless, this is a crucial missing variable as more than half of the population in LMIC (SSA included) live in rural areas. ${ }^{44}$

All 11 studies calculated direct medical costs, and our results suggest that direct cost is more often measured and is usually higher than indirect costs. Direct costs are easier to measure than indirect costs, especially in countries like those included in this study where many people are involved in the informal and subsistence economy. Inconsistency in measuring productivity losses of RTI victims and their caregivers can also limit the ability to capture indirect costs and the under-reporting of RTIs economic burden. Another challenge in measuring all costs in countries in Africa is the general under-reporting of injuries. This has been often identified as a challenge in understanding the burden of RTIs. ${ }^{745-47}$

This review found that the economic burden associated with RTIs is considerably high, especially when considering poverty levels in many SSA countries. The median 
costs of illness in this study was found to be about INT $\$ 10$ 906 per injury and INT $\$ 1291.5$ per hospitalisation. For countries in the SSA region that is home to more than $50 \%$ of the world's poor with limited or no access to insurance and social protection schemes, ${ }^{13}{ }^{48}$ such spending could lead to catastrophic expenditure and impact national development.

In one of the reviewed studies done in Nigeria, the average cost per patient per hospitalisation was estimated to be INT $\$ 588 .^{38}$ They also reported that $86 \%$ of the RTC victims included in their study had catastrophic expenditures (ie, spending more than $10 \%$ of the family's annual income on treatment for the injuries). ${ }^{38}$ In a country in which more than $50 \%$ of the population live in extreme poverty (living below $\$ 1.90 /$ day), ${ }^{450}$ it is highly likely that the cost of treatment for an RTC victim will lead to a worsening state of poverty and possibly, debts.

The second objective of this study was to review the quality of reporting the evidence and methods used to estimate and report the costs. This study found unsatisfactory reporting of methodology and poor quality of existing evidence on RTIs in SSA. As previously presented, less than $50 \%$ of the reviewed studies met half of the modified CHEERS checklist criteria. Only one study met more than $80 \%$ of the criteria. ${ }^{36}$ The poorly met criteria which need to be improved were reporting analysis perspectives taken, analytical methods including performing sensitivity analysis and characterising uncertainty. These weaknesses are consistent with previous cost of illness ${ }^{5152}$ and economic evaluations ${ }^{53} 54$ reviews conducted in SSA.

Only one study ${ }^{36}$ in this systematic review reported and described sensitivity analysis and dealt with uncertainty. Lack of sensitivity analyses is not limited to RTIs economic analyses; Mutyambizi et $a \tilde{l}^{11}$ also noted the lack of reporting of sensitivity analysis as a significant limitation in their systematic review on the cost of illness of diabetes in Africa. Best practises include detailing the importance of performing sensitivity analysis and characterising uncertainty. ${ }^{245}$

In reviewing the methods used to identify and estimate cost of resources, more than half $(63 \%)$ of the studies under review did not explicitly state their costing methods. In cases where it was stated, information on how resources were identified, measured or valued was not well detailed. A possible explanation for this could be the lack of standardisation and formal validation for estimating resources and costing methodologies. ${ }^{52}$ Nevertheless, it is best practise to describe methods used to estimate resources and unit costs. ${ }^{24}{ }^{55}$ This allows generalisability of results and replication of methods, and thus, heterogeneity or absence of costing methodologies is problematic for generalisability.

We also found considerable variations in the units of cost and components used to estimate the cost. More than half of the studies reviewed did not include or only partially included a breakdown of the components of cost. Even though a comparability analysis was done to attempt adjusting for this, the costs may not be directly comparable to each other. Unit costs can only be directly comparable to similar units and it is difficult to directly compare costs in which the cost components are not known. Though there are no standardised definitions of direct and indirect costs and their components, detailing these components allow comparability, transparency and credibility of results. ${ }^{55}$ Thus, some of the costs reported in the reviewed studies may have been over or underestimated, and in the absence of cost components, the reliability of the results comes into question. Wessen et al reported similar variations in cost and cost descriptions in their systematic review of RTIs in LMICs. ${ }^{43}$

Regarding the third objective of this study, which was to identify the factors associated with the costs of RTIs, our results show the paucity of data. Two studies did a sensitivity analysis, but only one of those clearly stated the factors associated with the cost based on their analysis. ${ }^{36}$ One study did not report performing a sensitivity analysis but clearly stated factors that drive the cost ${ }^{37}$ and hence, it is unclear how these drivers were identified in their study. Surgical sundries (especially implants), prolonged hospital stays and severity of injury were observed to be the most common associations that drive costs in this review, but they differed by and within countries. The only driver of cost highlighted in studies done in the same country was surgical sundries in South Africa. ${ }^{39} 40$

\section{LIMITATIONS}

The limitations noted in this review are a direct consequence of the limitations in the quantity and quality of the existing evidence on the topic. Due to the heterogeneity of the cost components, lack of transparency in resource estimation, variability in unit costs and costing methods, it is difficult to compare the costs across different countries directly. Likewise, the number of studies and countries included in this literature review is quite small, owing to the lack of existing data on the topic published in English and is not entirely representative of SSA.

\section{CONCLUSION}

The findings highlight limited evidence on the cost and economic burden of RTIs in SSA. The findings also show that the quality of the published data on RTIs is quite unsatisfactory and does not meet the criteria for best practises for reporting costs and costing, which is problematic for the credibility and generalisability of the results. Nevertheless, considering the high and increasing rate of RTIs in SSA, the available evidence suggests that the economic burden of RTIs in SSA can be substantially high.

More research is needed to understand the impact of this public health challenge, its costs to RTI victims and economic development and to inform and guide policymakers in designing interventions for road safety and injury prevention in SSA. 
Twitter Marcella Farrelle Dorothea Ryan-Coker @EmmArr_Cee, Justine Davies @ drjackoids and Hassan Haghparast-Bidgoli @HHaghparast

Contributors MFDR-C and HH-B contributed equally to the conception and design of this systematic review. MFDR-C, GR and $\mathrm{HH}-\mathrm{B}$ contributed to the data extraction and analysis. MFDR-C wrote the first draft of the manuscript. MH, JD, MN, DHM and $\mathrm{HH}-\mathrm{B}$ revised the manuscript critically and provided critical comments on the interpretation of findings. All authors approved the final manuscript for publication.

Funding The authors have not declared a specific grant for this research from any funding agency in the public, commercial or not-for-profit sectors.

Competing interests None declared.

Patient consent for publication Not required.

Provenance and peer review Not commissioned; externally peer reviewed.

Data availability statement Data sharing not applicable as no data sets generated and/or analysed for this study. No data are available.

Supplemental material This content has been supplied by the author(s). It has not been vetted by BMJ Publishing Group Limited (BMJ) and may not have been peer-reviewed. Any opinions or recommendations discussed are solely those of the author(s) and are not endorsed by BMJ. BMJ disclaims all liability and responsibility arising from any reliance placed on the content. Where the content includes any translated material, BMJ does not warrant the accuracy and reliability of the translations (including but not limited to local regulations, clinical guidelines, terminology, drug names and drug dosages), and is not responsible for any error and/or omissions arising from translation and adaptation or otherwise.

Open access This is an open access article distributed in accordance with the Creative Commons Attribution Non Commercial (CC BY-NC 4.0) license, which permits others to distribute, remix, adapt, build upon this work non-commercially, and license their derivative works on different terms, provided the original work is properly cited, appropriate credit is given, any changes made indicated, and the use is non-commercial. See: http://creativecommons.org/licenses/by-nc/4.0/.

\section{ORCID iDs}

Marcella Farrelle Dorothea Ryan-Coker http://orcid.org/0000-0001-8316-2803

Hassan Haghparast-Bidgoli http://orcid.org/0000-0001-6365-2944

\section{REFERENCES}

1 World Health Organisation (WHO). Global Status report on road safety [Online], 2018. Available: https://www.who.int/violence_injury_ prevention/road_safety_status/2018/en/ [Accessed 29 Aug 2019].

2 World Health Organization (WHO). Global Health Estimates 2016: Disease burden by Cause, Age, Sex, by Country and by Region, 2000-2016 [Online], 2018. Available: http://www.who.int/healthinfo/ global_burden_disease/estimates/en/index1.html [Accessed 29 Aug 2019].

3 Hyder AA, Paichadze N, Toroyan T, et al. Monitoring the decade of action for global road safety 2011-2020: an update. Glob Public Health 2017:12:1492-505.

4 United Nations Development Program (UNDP). Sustainable Development Goals [Online], 2019. Available: https://www.undp. org/content/undp/en/home/sustainable-development-goals.html [Accessed 29 Aug 2019].

5 Peden M, Scurfiled R, Sleet D. World report on road traffic injury prevention. Geneva, Switzerland: World Health Organization, 2004.

6 Onywera VO, Blanchard C. Road accidents: a third burden of 'disease' in sub-Saharan Africa. Glob Health Promot 2013;20:52-5.

7 Bhalla K, Harrison J, Shahraz S. Burden of road injuries in subSaharan Africa. Department of global health and population. Boston, MA: Harvard School of Public Health, 2013.

8 World Health Organization (WHO). The Global Burden of Disease: 2004 Update [Online], 2008. Available: https://www.who.int/ healthinfo/global_burden_disease/GBD_report_2004update_full.pdf? $\mathrm{ua}=1$ [Accessed 29 Aug 2019].

9 World Road Association. Socio-economic cost of road traffic crashes: Evaluating costs and the value of injury prevention. [Online], 2019. Available: https://roadsafety.piarc.org/en/strategic-globalperspective-scope-road-safety-problem/socio-economic-costs [Accessed 29 Aug 2019].

10 Sangowawa AO, Owoaje ET, Ekanem SEU, et al. Economic costs of motorcycle injury among crash-involved commercial motorcyclists in Oyo state, Nigeria. Afr J Med Med Sci 2011;40:385-91.

11 Yamey G, Fewer S, Beyeler N. Achieving a "Grand Convergence" in Global Health by 2035: Rwanda Shows the Way Comment on
"Improving the World's Health Through the Post-2015 Development Agenda: Perspectives From Rwanda". Int J Health Policy Manag 2015;4:789-91

12 Mock C, Arreola-Risa C, Quansah R. Strengthening care for injured persons in less developed countries: a case study of Ghana and Mexico. Inj Control Saf Promot 2003;10:45-51.

13 Marquez PV, Farrington JL. The challenge of non-communicable diseases and road traffic injuries in sub-Saharan Africa. An overview. Washington, DC: The World Bank, 2013.

14 World Health Organisation (WHO). Road Traffic Injuries; Key Facts [Online], 2018. Available: https://www.who.int/news-room/factsheets/detail/road-traffic-injuries [Accessed 29 Aug 2019]

15 Peden M, Kobusingye O, Monono ME. Africa's roads: the deadliest in the world. S Afr Med J 2013;103:228-9.

16 Jacobs G, Thomas AA, Astrop A. Estimating global road fatalities (TRL report 445 2000). Crowthorne: Transport Research Laboratory, 2000.

17 Bhalla K, Shahraz S, Abraham J. Road injuries in 18 countries. Department of global Heath and population. Boston, MA, USA: Harvard School of Public Health, 2011.

18 World Bank. Data: Sub-Saharan Africa [Online], 2019. Available: https://data.worldbank.org/region/sub-saharan-africa [Accessed 29 Aug 2019].

19 Moher D, Liberati A, Tetzlaff J, et al. Preferred reporting items for systematic reviews and meta-analyses: the PRISMA statement. BMJ 2009;339:b2535

20 Liberati A, Altman DG, Tetzlaff J, et al. The PRISMA statement for reporting systematic reviews and meta-analyses of studies that evaluate healthcare interventions: explanation and elaboration. BMJ 2009;339:b2700.

21 Rinaldi G, Kiadaliri AA, Haghparast-Bidgoli H. Cost effectiveness of HIV and sexual reproductive health interventions targeting sex workers: a systematic review. Cost Eff Resour Alloc 2018;16:63.

22 Haghparast-Bidgoli H, Kiadaliri A, Skordis-Worrall J. Do economic evaluation studies inform effective healthcare resource allocation in Iran? A critical review of the literature. Cost Eff Resour Alloc 2014;12:15

23 Drummond MF, Sculpher MJ, Claxton K. Methods for the economic evaluation of health care programmes. 4th ed. Oxford: Oxford University Press, 2015.

24 Husereau D, Drummond M, Petrou S, et al. Consolidated health economic evaluation reporting standards (cheers) statement. Int J Technol Assess Health Care 2013;29:117-22.

25 Rinaldi G, Hijazi A, Haghparast-Bidgoli H. Cost and costeffectiveness of mHealth interventions for the prevention and control of type 2 diabetes mellitus: a protocol for a systematic review. BMJ Open 2019;9:e027490.

26 World Bank. Data: Consumer Price Index [Online], 2019. Available: http://data.worldbank.org/indicator/FP.CPI.TOTL [Accessed 29 Aug 2019]

27 World Bank. Data: Official Exchange Rate (LCU per US\$, period average) [Online], 2019. Available: http://data.worldbank.org/ indicator/PA.NUS.FCRF?page=1 [Accessed 29 Aug 2019].

28 World Bank. Data: PPP Conversion factor, GDP (LCU per international \$) [Online], 2019. Available: http://data.worldbank.org/ indicator/PA.NUS.PPP [Accessed 29 Aug 2019].

29 Kirch W, ed. Encyclopedia of Public Health; Direct Cost [Online]. Springer, Dordrecht, 2008.

30 Drummond MF, Sculpher MJ, Torrance GW, eds. Methods for the economic evaluation of health care programme. Oxford University Press: Oxford:, 2005

31 Olukoga A. Cost analysis of road traffic crashes in South Africa. Inj Control Saf Promot 2004;11:59-62.

32 Agbor AM, Azodo CC, Ebot EB, et al. Dentofacial injuries in commercial motorcycle accidents in Cameroon: pattern and cost implication of care. Afr Health Sci 2014;14:77-82.

33 Kudebong M, Wurapa F, Nonvignon J, et al. Economic burden of motorcycle accidents in northern Ghana. Ghana Med $J$ 2011;45:135-42

34 Saidi H, Mutisto BK. Motorcycle injuries at a tertiary referral hospital in Kenya: injury patterns and outcome. Eur J Trauma Emerg Surg 2013;39:481-5

35 Allen Ingabire JC, Petroze RT, Calland F. Profile and economic impact of motorcycle injuries treated at a university referral hospital in Kigali, Rwanda. Rwanda Med J 2015;72:5-11.

36 Matiwane BP, Mahomed O. Cost analysis of road traffic crashes in a tertiary hospital in Mpumalanga Province, South Africa. Cogent Med 2018;5:1549800.

37 Juillard $\mathrm{C}$, Labinjo $\mathrm{M}$, Kobusingye $\mathrm{O}$, et al. Socioeconomic impact of road traffic injuries in West Africa: exploratory data from Nigeria. Injury Prevention 2010;16:389-92. 
38 Urua U, Osungbade $\mathrm{K}$, Obembe T, et al. A cost analysis of road traffic injuries in a tertiary hospital in south-west Nigeria. Int $J$ Inj Contr Saf Promot 2017;24:510-8.

39 Parkinson F, Kent SJW, Aldous C, et al. The hospital cost of road traffic accidents at a South African regional trauma centre: a microcosting study. Injury 2014;45:342-5.

40 Olukoga A. The socioeconomic costs of road traffic accidents in Ethekwini (Durban) Municipality, South Africa. Journal of Interdisciplinary Economics 2004;15:301-8.

41 Ipingbemi O. Spatial analysis and socio-economic burden of road crashes in south-western Nigeria. Int $\mathrm{J}$ Inj Contr Saf Promot 2008;15:99-108.

42 World Health Organization (WHO).. Disease and injury country estimates: Burden of Disease [Online], 2011. Available: http://www. who.int/healthinfo/global_burden_disease/estimates_country/en/ index.html [Accessed 29 Aug 2019].

43 Wesson HKH, Boikhutso N, Bachani AM, et al. The cost of injury and trauma care in low- and middle-income countries: a review of economic evidence. Health Policy Plan 2014;29:795-808.

44 World Bank. World bank data urban population. Washington, DC: The World Bank, 2012.

45 Wang Q, Brenner S, Kalmus O, et al. The economic burden of chronic non-communicable diseases in rural Malawi: an observational study. BMC Health Serv Res 2016;16 https://bmchealthservres. biomedcentral.com/articles/

46 Ameratunga S, Hijar M, Norton R. Road-Traffic injuries: confronting disparities to address a global-health problem. The Lancet 2006;367:1533-40.
47 Salifu M, Ackaah W. Under-Reporting of road traffic crash data in Ghana. Int J Inj Contr Saf Promot 2012;19:331-9.

48 Wadhwa $\mathrm{D}$. The number of extremely poor people continues to rise in Sub-Saharan Africa. World Bank Blogs, 2018. Available: https:// blogs.worldbank.org/opendata/number-extremely-poor-peoplecontinues-rise-sub-saharan-africa [Accessed 29 Aug 2019].

49 World Bank. Poverty [Online], 2019. Available: https://www. worldbank.org/en/topic/poverty/overview [Accessed 29 Aug 2019].

50 World Bank. Country Profile: Nigeria [Online], 2010. Available: https:// databank.worldbank.org/views/reports/reportwidget.aspx?Report_ Name=CountryProfile\&ld=b450fd57\&tbar=y\&dd=y\&inf=n\&zm=n\& country=NGA [Accessed 29 Aug 2019].

51 Mutyambizi C, Pavlova M, Chola L, et al. Cost of diabetes mellitus in Africa: a systematic review of existing literature. Global Health 2018;14:3.

52 Molinier L, Bauvin E, Combescure C, et al. Methodological considerations in cost of prostate cancer studies: a systematic review. Value Health 2008;11:878-85.

53 Gavaza P, Rascati KL, Oladapo AO, et al. The state of health economic evaluation research in Nigeria: a systematic review. Pharmacoeconomics 2010;28:539-53.

54 Gavaza P, Rascati KL, Oladapo AO, et al. The state of health economic research in South Africa: a systematic review. Pharmacoeconomics 2012;30:925-40.

55 Drummond MF, Jefferson TO. Guidelines for authors and peer reviewers of economic submissions to the BMJ. BMJ 1996;313:275-83. 